\title{
Investigation and comparison of the seismic behavior of steel structure of moment frame with/without CFT column
}

\author{
Mohsen Oghabi ${ }^{1}$, Farshad Shekari ${ }^{2 *}$ \\ ${ }^{1-D e p a r t m e n t ~ o f ~ C i v i l ~ E n g i n e e r i n g, ~ C o l l e g e ~ o f ~ E n g i n e e r i n g, ~ K e r m a n s h a h ~ B r a n c h, ~}$ \\ Islamic Azad University, Kermanshah, Iran \\ 2-Department of Civil Engineering, College of Engineering, Kermanshah Branch, \\ Islamic Azad University, Kermanshah, Iran
}

\begin{abstract}
In the present research, the seismic behavior of steel structure of moment frame with CFT column has been evaluated. Finite element method has been used for numerical modeling. In the modeling, the surface and volume elements were used for steel and concrete, respectively. One, two, and three-story frames with and without CFT column under different earthquakes were investigated through dynamic analysis of the time history. The results show that the steel frame with CFT column, in terms of energy dissipation, has better behavior than the steel frame. The roof displacement in the different frames with CFT is less than that of the steel frame which indicate the improved performance of the frame. Using the CFT column in the column, in comparison with steel column, has led an increase in the bearing capacity of the structure under the earthquake. By adding the concrete to the column, the failure status of the structure will change. In the model with CFT, the failure occurs mainly in the location of the panel zone, while in the steel column under earthquake, the buckling occurs in the column. The reason for that may be due to steelconcrete interaction, which in turn, will increase the bearing capacity of the CFT column. Presence of CFT column in the steel frames will result in increased bearing capacity of the frame. Filling the steel frame with concrete prevents the inward buckling of the column and delays the local buckling of the steel wall.
\end{abstract}

Keywords: concrete filled steel column, seismic loading, failure, buckling, roof drift.

\section{Introduction}

Choosing the type of consumable materials in the structure is one of the most decisions of every civil engineers. This depends on important factors include structure type, cost of materials, ease of implementation and project engineering economic. In every structure, the main and key strategy in all design and operation steps is to achieve the best performance of the structure and the most desirable cost for the project. Concrete is a material with high stiffness, low-cost and high resistant against fire, and steel is a high ductile, high-strength and low weight material. However, using only the steel in constructing the columns specially in the tall structures is uneconomic. Also, tall structures with steel columns have relatively high lateral deformations and low resistance against fire. Using only the concrete in the columns of the tall buildings occupied more space in lower stories and has the relatively higher weight, compare with steel columns, and due to the brittle and fragile nature of concrete, the constructed structure has less deformation and the strength loss will be created in the seismic loads. The smart combination of these materials will result in a more effective and more efficient system than a system composed of each of them separately. This system is introduced by phrases such as composite and/or dual system. In recent years, composite systems have been successfully used in columns, beams, and slabs with medium and large openings in buildings and also base and beams of the bridges. Using the composite columns, due to the proper and simultaneous use of concrete and steel, is increasingly implemented in structural systems all around the world. Composite columns not only have several advantages in construction, specially in terms of speed and economy but also leads a considerable improvement in mechanical properties of the structural elements compare with concrete and steel reinforced elements. If the composite columns are a part of a complex structural system, some other advantages can be expected from them. As an example, if a proper connection is provided between the column and roof system, these connections have higher strength and better behavior, which will lead to an increase in in the resistance as well as creating an additional constraint. One of the operational complications in these types of columns is the coordination of operational factors of concrete and steel and how to connect the beam to column. The advantages of such columns include: high construction speed, no need for a frame, reduced load on the foundation, increased useful space and reduced costs of construction and maintenance. These advantages have led to increasingly design and operate such columns. Generally, it is hoped that concrete-filled steel columns developed in the future since there are several types of research done on the improvement of operations of such structures. 
The purposes of the present study are as follow:

- Investigation the effect of the presence of concrete in a steel frame in the steel column and its effect on the ductility and energy absorption capacity.

- Comparing the moment frame with and without concrete-filled column under the seismic loading.

- Investigation the effect of the number of stories on the behavior of frames with and without concretefilled column.

- Study the failure mode in the moment frame structure for samples with and without concrete-filled steel column.

- Study the effect of concrete-filled steel column on the failure mode of the structure under earthquake.

\section{Literature Review}

Frank et al. (2004) investigated the behavior of concrete-filled steel columns under cyclic lateral loading. The results showed that the cohesion between concrete and steel as well as the loading end conditions do not affect the beam-column buckling capacity. However, the capacity of the short columns without adhesion and with steel wall has is higher compares with a sample with adhesion [1].

The concrete-steel composite columns gradually became popular and given the several advantages of these columns, use of them in the tall building has increased severely. The Filled double-layered steel tubes are composed of two concentric tubes in which the concrete is enclosed. The steel tubes can have the circular, square, oval, and polygon section. Also, this type of structures can be cone-shaped; means that by increasing or reducing the height, its section area decreases or increases. This shape of the structure can be used in the sea bed tubes, foundations of offshore platforms in deep, and large-diameter columns and structures exposed to ice. This type of enclosed section has high bending stiffness which prevents the instabilities under the external pressures [2].

In past, some studies have been done on the short columns to understand the composite performance of the steel tubes and concrete enclosed between them. The hollow space ratio, the slender ratio of internal and external tubes, the width of tubes, concrete strength, and strength of steel tubes are main parameters affecting the short steel columns filled with concrete [3,7].

Xiao-Ling Zhao (2009) obtained the following results:

1. An increase in ductility and energy absorption in CFDSTs under pressure were observed.

2. The behavior of short-columns of the tall structures was described according to composite performance between the steel tubes and the core concrete.

3. The failure mode observed in concrete-filled double-layered tubes was local buckling along with the shear failure of filled concrete.

4. The internal tubes do not affect the confinement effect. There is confinement stress on the concrete enclosed between two tubes, and its intensity is about 0.05 times the concrete cylindrical strength.

Wei-bin Yuan (2010), addressed the analysis of concrete-steel tube interaction in the composite column. It was concluded that the hollow ratio is more effective on the concrete stress for circular short column [6].

Jun-jie Yang (2010), used the U-PVC tube as the internal tube of the concrete-filled double-layered columns. In their investigations, they observed the following results:

1. Under the compression load, CFDSCT column has shown the initial elastic deformation, then follows the nonlinear deformation until reaching the load peak point. After the peak point, with an increase in deformation, the load decreases.

2. Usually, fracture of CFDSCT columns results from the failure of external steel tubes which is due to combined axial pressure and the internal pressure of concrete expansion. The failure mode of external steel tube includes external local buckling, local buckling and buckling interaction and yield of steel.

3. There was no failure observed in the PVC-U internal tube.

4. From finite element analysis, it was found that some cracks have occurred in the concrete before steel failure. In their studies, the use of PVC-U tubes instead of the internal tube in CFDST column was proved. Due to the advantages of PVC-U tubes such as low cost, good ductility, ease construction and the possibility of using the tube services (facilities and so on), this can be proved that PVC-U tube can be practically a good offer.

Hassanein and Kharoob (2013) found that the available results of the test do not cover all ranges of the diameterto-width ratio of concrete-filled columns. Therefore, they carried out a nonlinear numerical simulation based on the finite element method to compensate the available results, their studies were done for different values of $\mathrm{D} / \mathrm{te}$ equal to 47,150 , and more than 150 [8].

Ho and Dong (2014) reinforced the CFDST column using the external ring and observed that by reducing the space between rings, the bear load capacity because the higher confinement pressure exerted on the internal concrete. The extent of ductility of CFDST columns confined with more rings is not higher than CFDST columns. 
The extent of elastic stiffness of CFDST columns confined with more rings is not higher than the non-confined CFDST columns [9].

Bridge and Oshea (2000) concluded that by increasing the eccentricity force, will improve the ductility of short columns. In the concrete-filled columns, an important effect of concrete is that the local buckling of steel wall is delayed and the concrete in confinement mode is capable of bears higher stresses and strains than the non-confined case. The advantages of the double-layered composite columns compare with the single-layered composite columns include less weight, higher ductility and bearing higher axial forces. The scenario which occurs in the most scientific problems in a reinforced concrete compression member is the coexistence of axial load and bending moment. In the reinforced concrete frames, by cast-in-place concrete, even if the openings of both sides of a column are same in size, because of variations of live load, the bending moment will occur in a column. Even in the case of using preconstructed columns, the vertical loads result from falling and rising the beams, a moment will occur in the column. Based on these facts, even in the cases wherein, theoretically, a pure axial load will apply on a reinforced concrete column, the regulations recommended that applying a bending moment is necessary so that an eccentricity besides the axial load [10].

Talebi et al. (2018), investigated a 3D nonlinear finite element (FA) model to study the response of concrete-filled tube columns (CFT) under the fires after an earthquake. In their modeling, they considered three consecutive steps include cyclic, thermal, and structural analyses. Three possible seismic damage scenarios have been considered. They have considered high damage level and assumed that while the column has maintained its overall stability after the earthquake, has reached $50 \%$ its lateral strength. The results showed that the damages of the upper area have no effect on the fire response of the damaged column. Besides, the column with a damaged middle opening has less strength under fire, due to concurrency of damage location.

Hanifehzadeh and Mousavi (2019), simulated the response of an SCS wall exposed to the near-field explosion load. The structural performance of a regular SCS panel which exposed to the near-field explosion load has been evaluated in terms of maximum damage and deformation. The maximum deformation, plastic strain, and damage mode have been investigated in different loading scenarios. The purpose of their study was to predict the structural reaction on SCS panel exposed to different explosions and identifying the optimal configuration in terms of concrete strength and plane thickness. The optimal parameter for each of the structural components is identified using a specific optimization method. It was concluded that using the proposed wall configuration compares with the regular walls will have better performance while its additional construction costs is insignificant [12].

Yang et al. (2019), carried out a case study of 491 test results of the CFT under axial load from the available literature. The obtained results were used to investigate the effect of loading conditions, diameter to width ratio, concrete type, and compression strength on the bearing capacity of CFT columns wherein the models were used for the stress of steel tubes through nonlinear regression. By using the analysis based on Von-Mises performance along with the proposed models for ring stress, a model was proposed for predicting the bearing capacity of CFT columns. The performance of the proposed model and the available model was investigated using the data bank. Since the model development trend was rational, the proposed model provided a more reasonable and accurate of bearing capacity of CFT columns in different loading conditions [13].

Xian et al. (2019) proposed a new type of confined base-column connections using metal packaging for limiting the external elements of the reinforced concrete and investigated the seismic behavior of both traditional and proposed (CFT) concrete column-base connections experimentally by conducting 8 tests. The samples were simulated in large scale under seismic loads. The tests parameters were mainly including thickness, height and flexural strength ratio of external elements with or without metal containers and shear nails. The effects of test parameters on the failure mode, response curves to load deformation, stiffness, strength, flexibility, ability to dissipate energy and distributing the strain of confined beam-base connections were investigated comprehensively. The results of the tests showed that with the proper design of beam-base connections, desire seismic behavior can be achieved and by using the metal packaging, the cracking of external parts of reinforced concrete can be prevented effectively [14].

Shariati et al (2020) carried out a numerical investigation on the behavior of concrete-filled tube columns under the axial pressure. They created a finite element (FE) model to simulate the behavior of CFT columns. By comparing the FE results and the tests, it was found that the numerical model can capture the desired conditions and can precisely predict the axial performance of the CFT columns. Also, with an increase in the thickness of the steel tubes, due to the higher effect, the bearing capacity of the columns has increased. By increasing the strength of concrete, with more cross-section, load-bearing capacity has increased compared with increasing the steel tube. In CFT columns with more cross-section, the strength of concrete is more than the load-bearing capacity which is more considerable in columns with welding point [15].

By studying the previous literature it can be concluded that the behavior of steel structures with moment frame with and without CFTCFT has not been yet investigated and needs to be investigated and studied. 


\section{Methodology}

To create the base model, ABAQUS software was used. For steel column and the concrete core, the surface and volumetric elements were used, which were modeled with the reduced integral equation with solid and brick elements with 3 degrees of freedom for volumetric model and S4R for the surface model. The reduced integration elements for meshing the model. Loading has been applied uniformly on the upper plane so that the load is applied in the opposite direction and as similar form with the cyclic loading protocol. The displacement control load is applied to the model. The upper and lower planes have been connected to the desired column via Tie command. In this research, the implicit dynamic analysis has been used. the concrete-steel interaction has been taken in to account. The contact algorithm was used to define the concrete-steel contact. The behavior of hard contact and penalty algorithm were used. The finite element analysis of CFT frame provides a better understanding of real behavior with minimum cost in minimum time. The test base model shown in Fig. (1) was used for modeling.

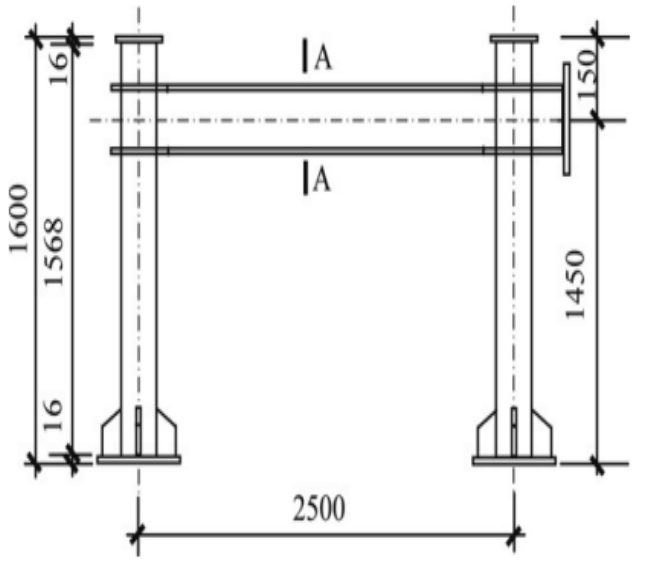

(a) Frame elevation.

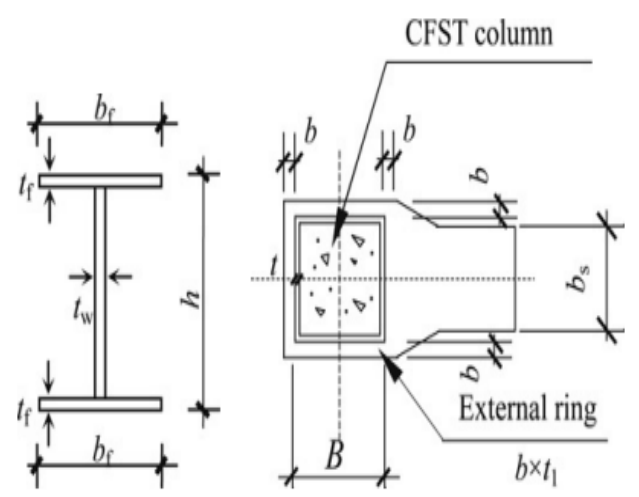

(b) A-A.

(c) Fabrication of joints.

Fig. 1. Dimensions and details of the test base model.

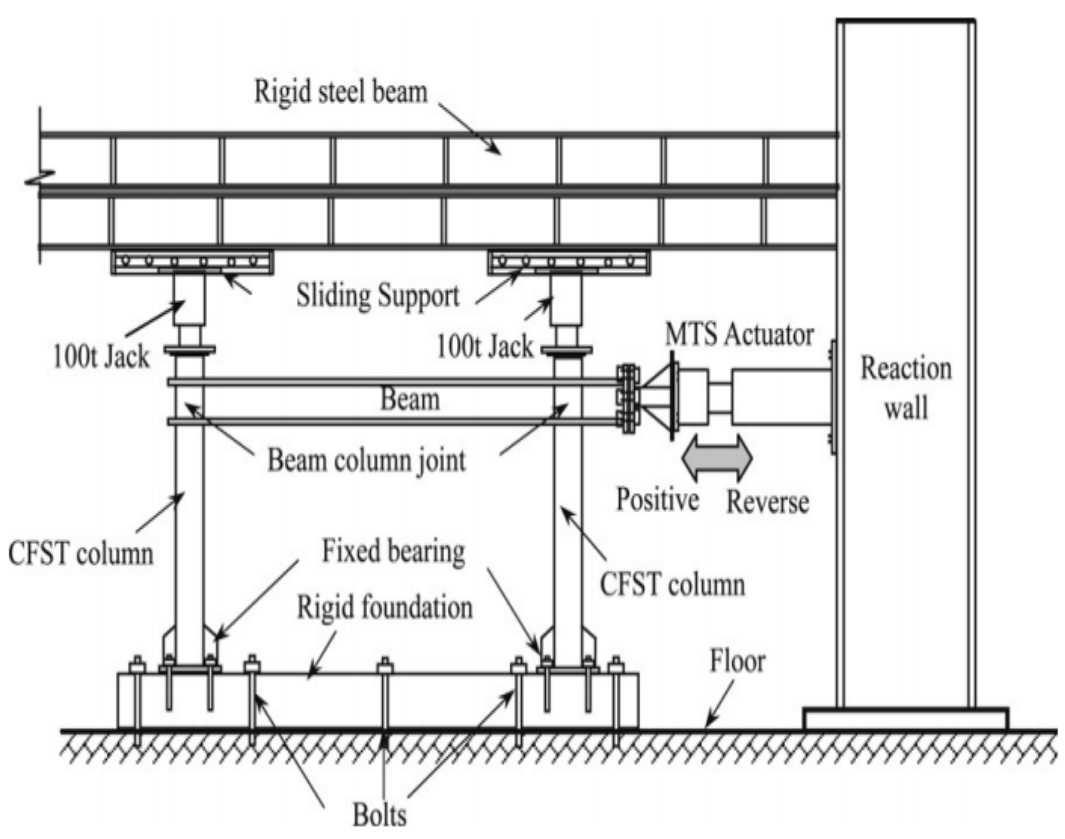

Fig. 2. Loading and support conditions in the test model.

\subsection{Materials' specifications}

The materials were modeled nonlinearly in the modeling software. The nonlinear behavior with plasticity behavior was considered for steel. For the plasticity model of concrete, the concrete damage plasticity model was used. 


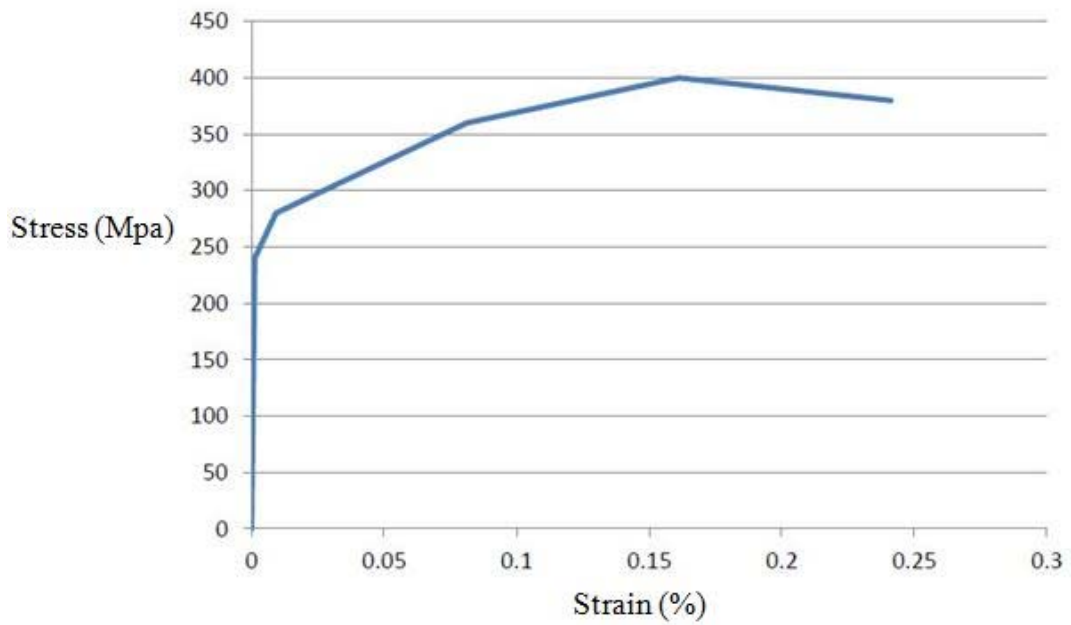

Fig. 3. Strain-stress curve of steel.

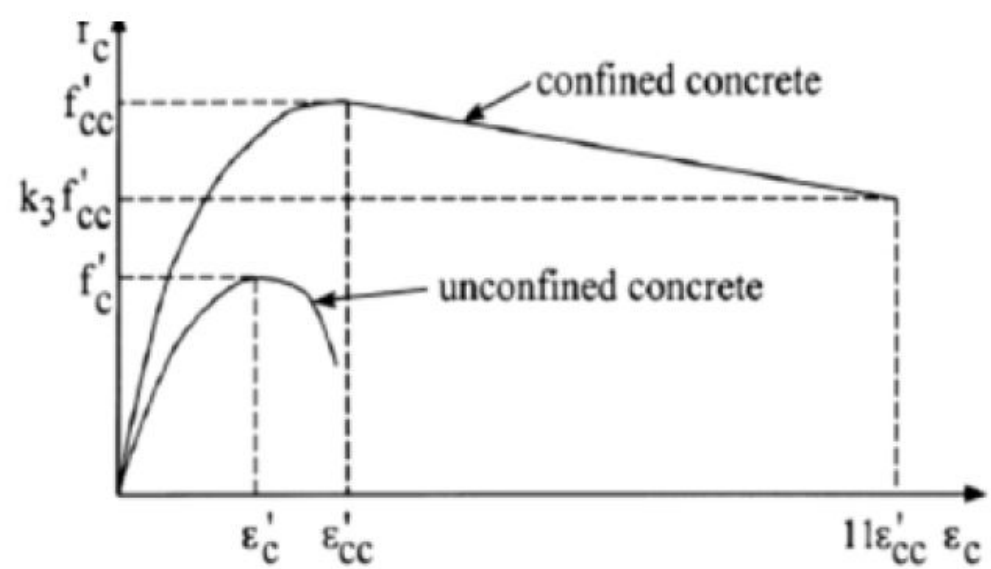

Fig. 4. The non-axial strain-stress curve of concrete.

\subsection{Loading and boundary conditions}

The support conditions were specified for the model. Fig. (5) shows the model of the concrete-filled column with the support conditions. The test conditions of the sample on the jack force were simulated. To do this, the sample was located on the frame under the displacement according to the SAC protocol. However, to apply the earthquake, the earthquake displacement was applied to the location of the columns' support.

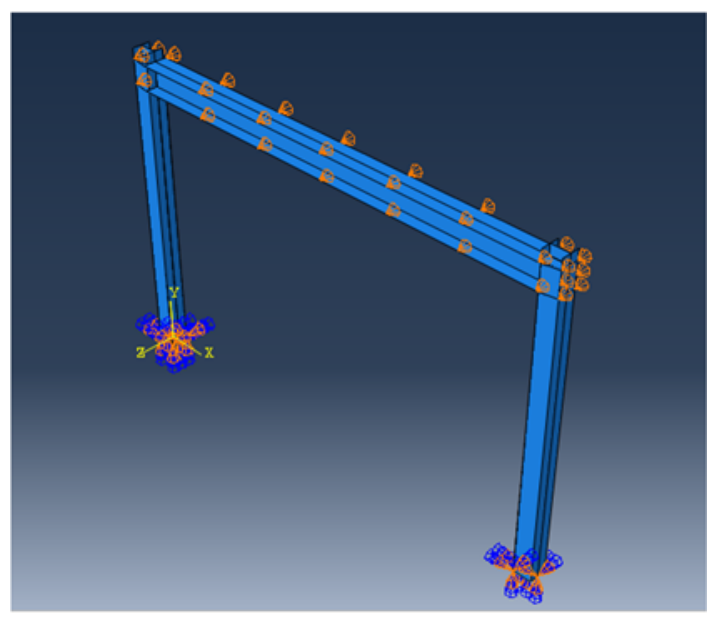

Fig. 5. A model with support conditions. 
Applying the load to the structure was done as the drift control. The SAC loading protocol was used. The cyclic loading pattern is shown in Fig. (6).

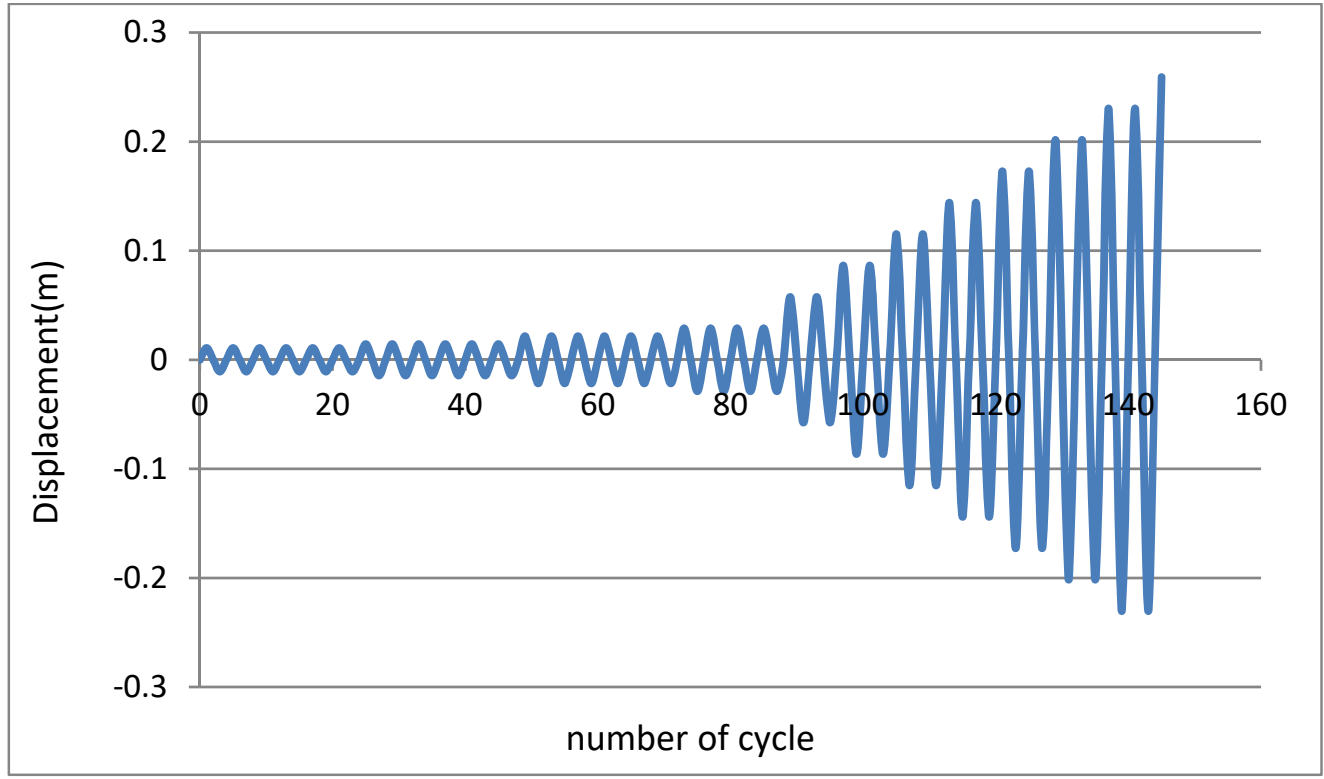

Fig. 6. Loading pattern

\section{Research results}

In this section, different samples have been investigated. For better comparison, the 1, 2, and 3-stories steel moment frames and concrete-filled columns were compared. First, the loading of frames was periodically and as displacement control and the results for studied frames were compared. Then, the studied samples were exposed to the displacement of some real earthquakes and the time-displacement and hysteresis curves of the samples were compared. The results are discussed in the following.

\subsection{Investigation of hysteresis behavior of models}

Hysteresis curves of two frames with and without concrete-filled columns have been compared. Fig. (7) and Fig. (8) show the energy dissipation curve of steel frame and energy dissipation of concrete-filled steel frame, respectively. As can be seen from these figures, the frame with reinforced concrete-filled steel column has higher energy dissipation and less strength loss. The behavior of steel moment frame with concrete-filled steel column is better in terms of energy dissipation.

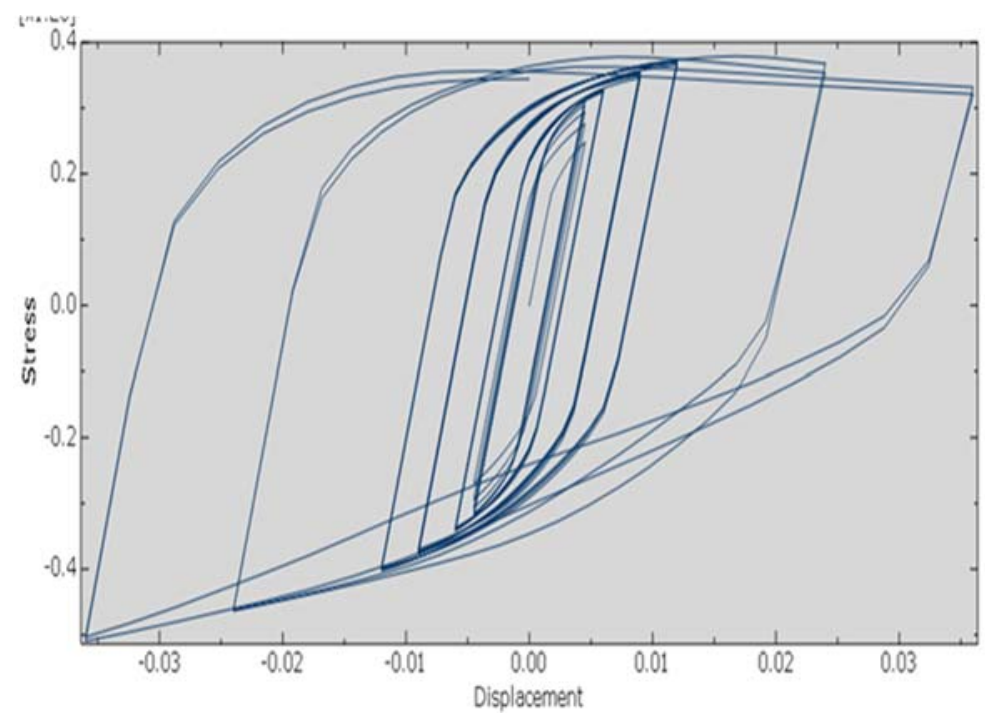

Fig. 7. Hysteresis curves of a frame without concrete-filled steel column. 


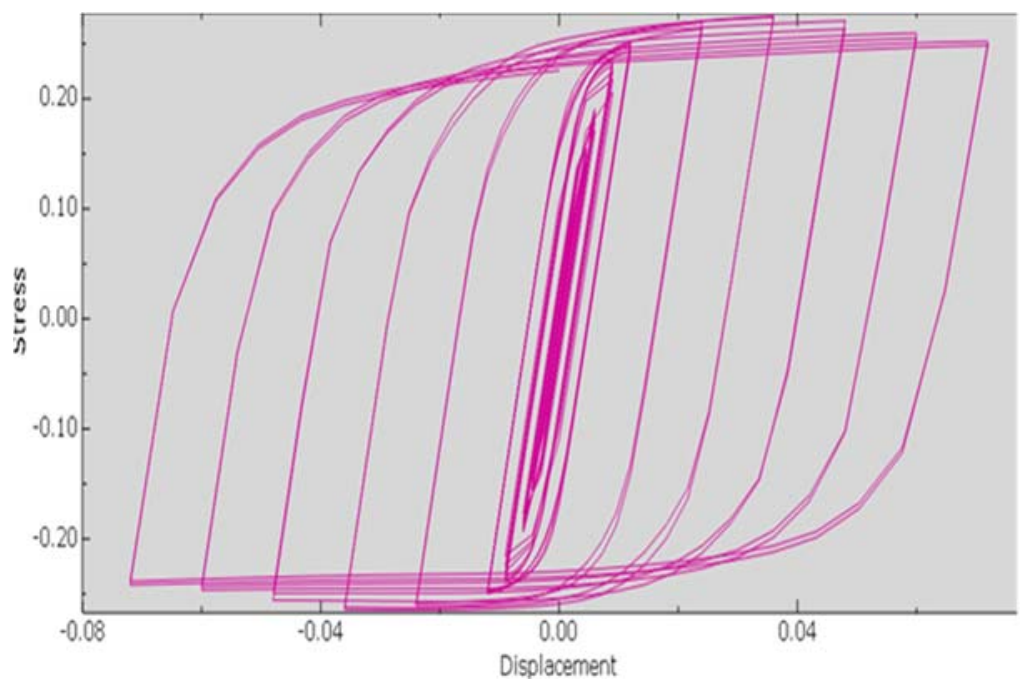

Fig. 8. Hysteresis curves of a frame with a concrete-filled steel column.

\subsection{Investigation of the seismic behavior od models}

Deformation and stress of samples without concrete-filled steel column are shown in Figs. (9)-(12). As can be seen from these figures, the nonlinear behavior with high energy dissipation level has occurred in the samples. The behavior in the concrete-filled sample is better since the surface confined to the residual rings in higher which indicates the higher energy dissipation in the frame with concrete-filled column.

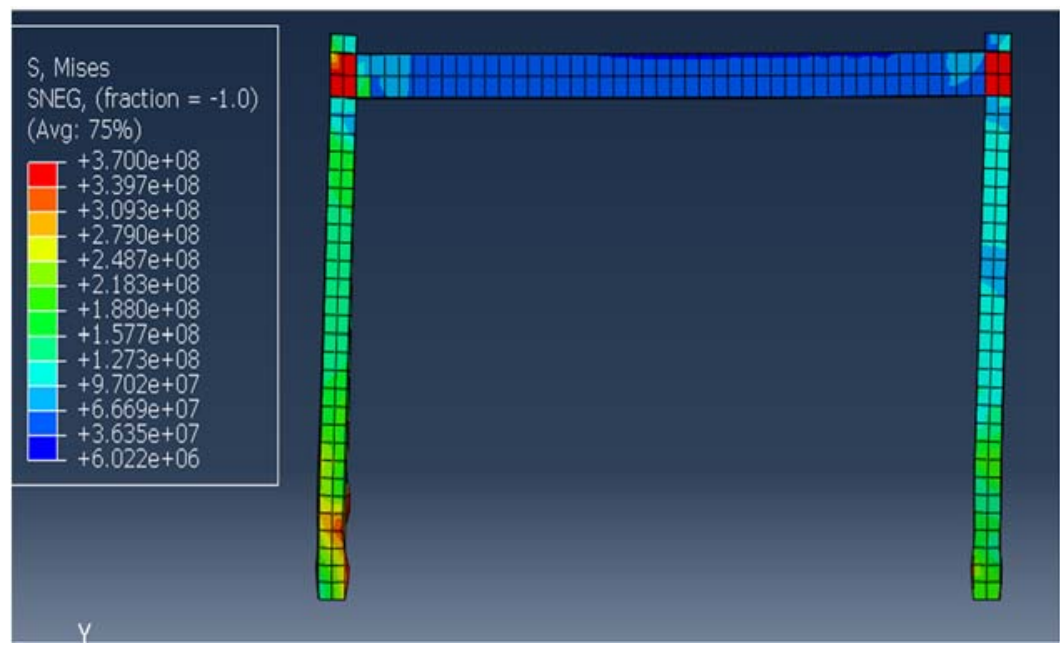

Fig. 9. Deformation of steel frame and buckling of the column under loading.

In Fig. (10), the column buckling in the near-earth location is entirely clear.

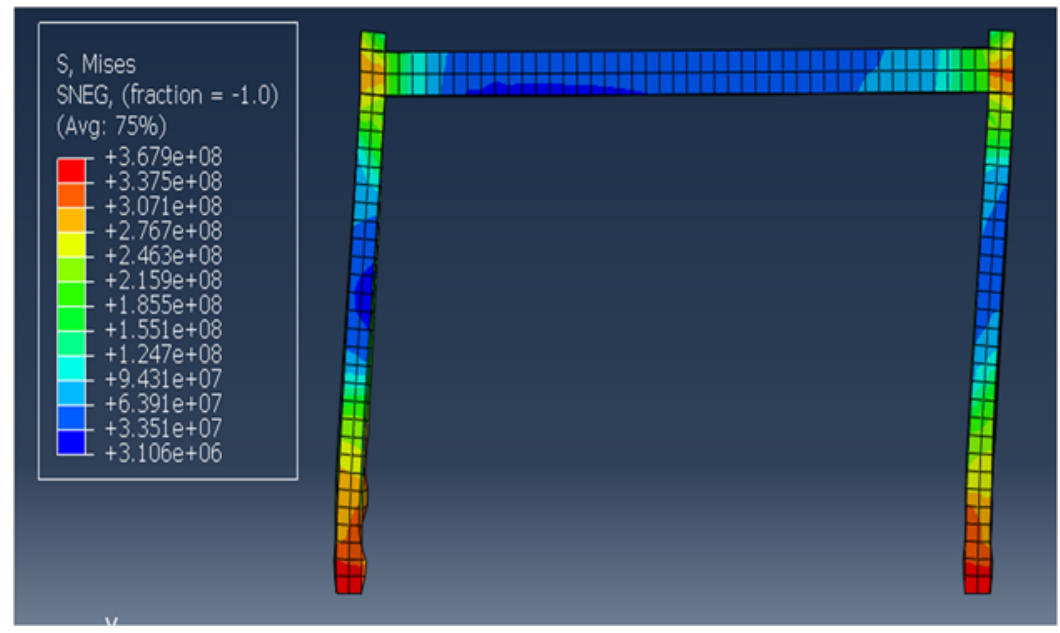

Fig. 10. An increase in the Von-Mises stress and buckling of columns. 


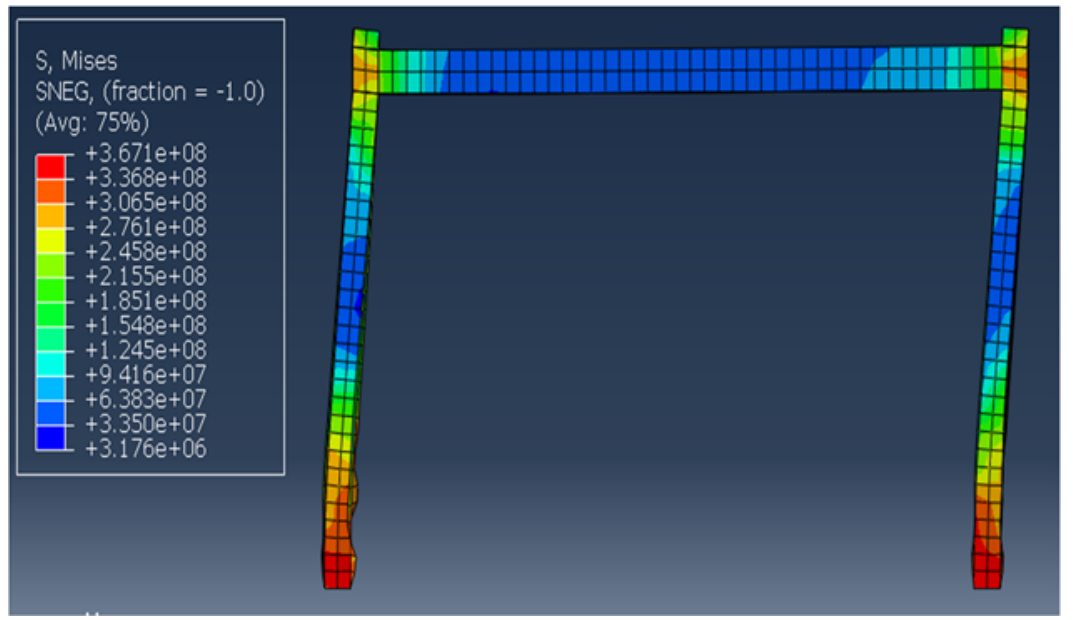

Fig. 11. Large deformation of a one-story steel frame and an increase in buckling in the location of columns.

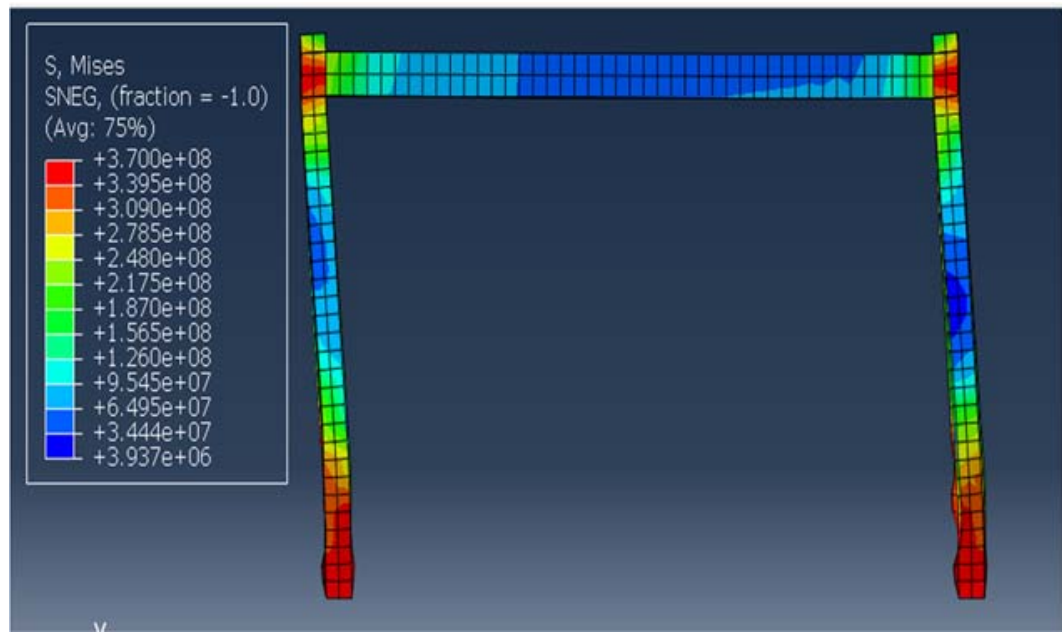

Fig. 12. Extensive yield stress in columns and beam-column panel zones in one-story frame.

Deformations of samples with concrete-filled column are shown in Figs. (13)-(16). As it is cleared in the figures, the presence of concrete in the steel column has led to a reduction in stress level and also an increase in the column capacity against the buckling. This is more obvious when the beam behavior became nonlinear in the beamcolumn connection location. Indeed, the presence of concrete in the steel column has concentrated the failure to the panel zone and near the beam-column connection, which indicates the improved frame behavior due to the presence of concrete.

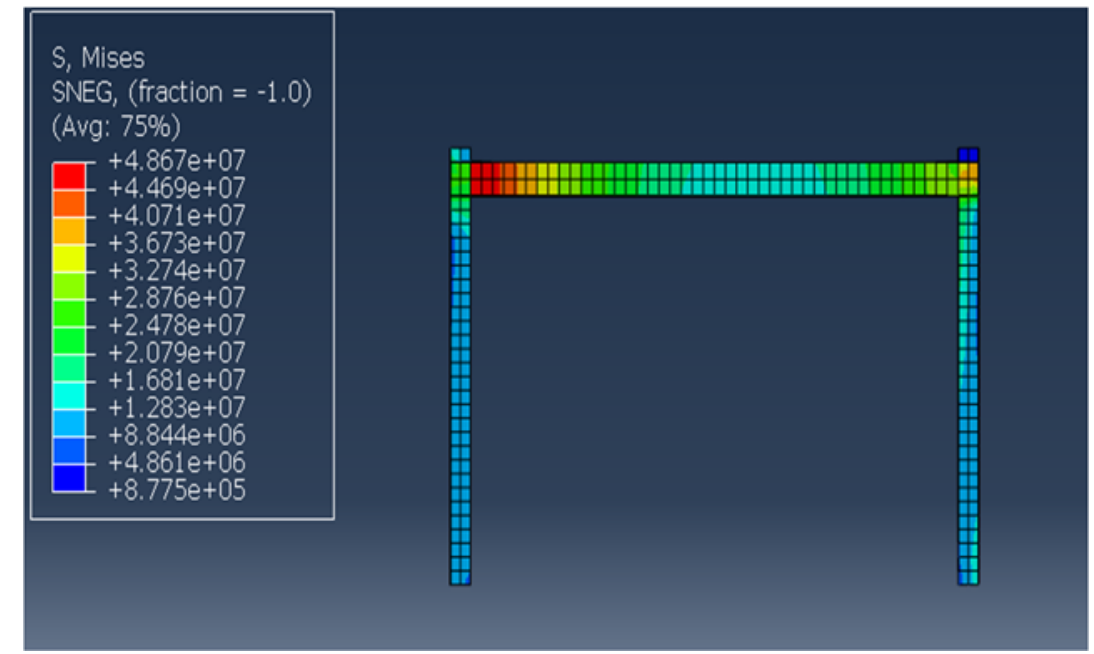

Fig. 13. Von-mises stress in the location of beam-column connection and the linear behavior in the concrete-filled column. 


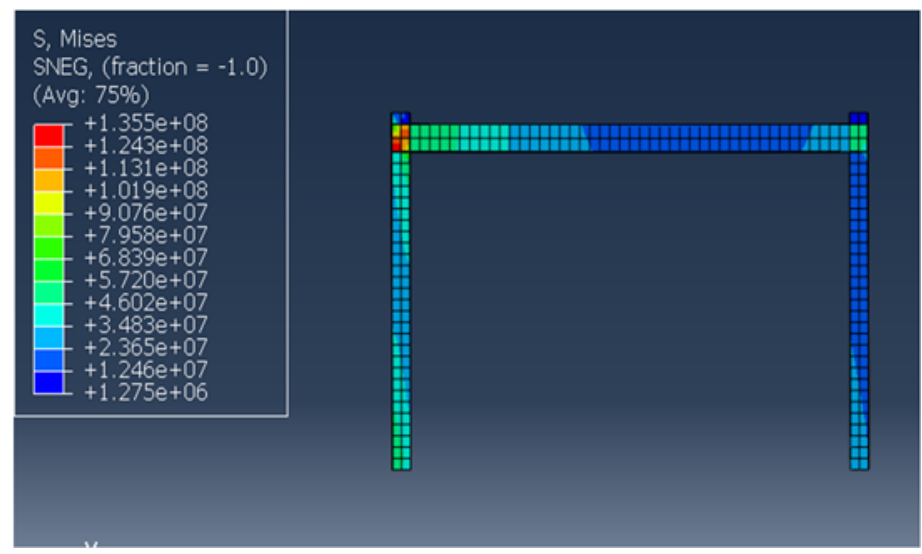

Fig. 14. Von-mises yield in the panel zone and the appropriate behavior of the column under loading.

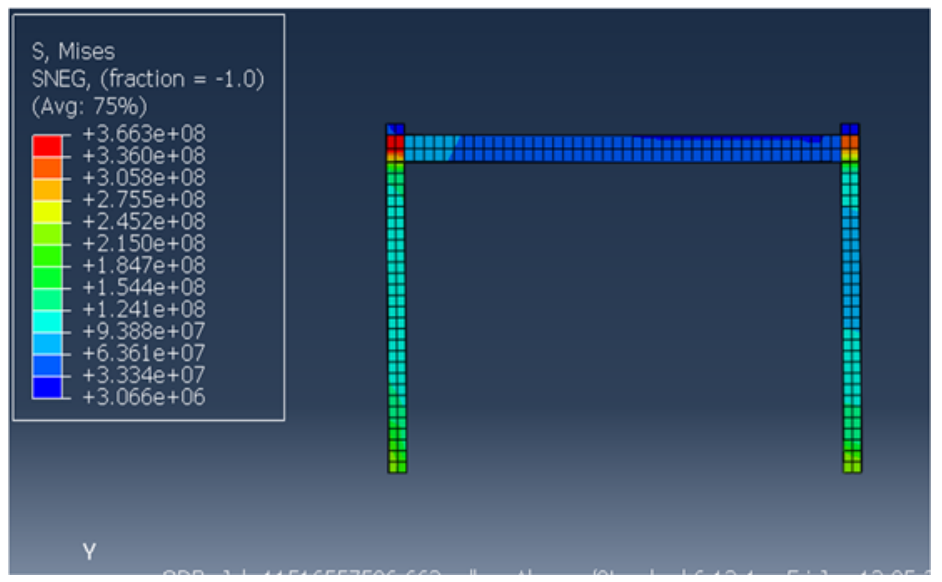

Fig. 15. Proper performance of the frame with concrete-filled frame and appropriate behavior of column.

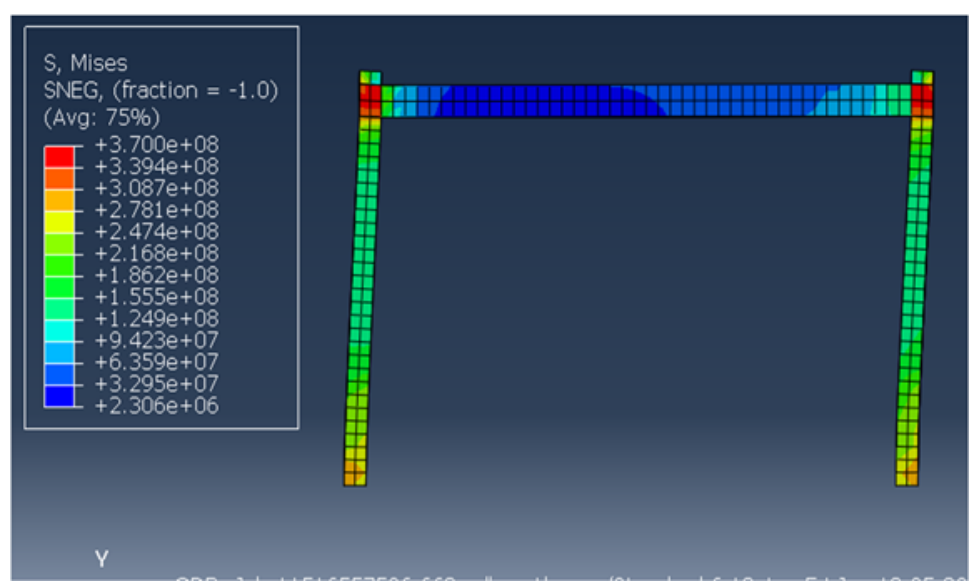

Fig. 16. Stress concentration in the panel zone and the appropriate behavior of the concrete-filled column.

Table 1 lists a summary of the results of the behavior of different frames under the earthquake. The 1,2, and 3stories frames under 4 different earthquakes were analyzed. The structure displacement for the number of stories and different earthquakes under the time history dynamic analysis are presented in Table 1. 
Table 1. Displacement of different models under earthquake.

\begin{tabular}{|c|c|c|c|c|}
\hline Analysis number & Model type & Earthquake & Number of story & Displacement(cm) \\
\hline 1 & STEEL & Chalfant Valley & 1 & 2 \\
\hline 2 & CFT & Chalfant Valley & 1 & 1.9 \\
\hline 3 & STEEL & Chalfant Valley & 2 & 4.2 \\
\hline 4 & CFT & Chalfant Valley & 2 & 4 \\
\hline 5 & STEEL & Chalfant Valley & 3 & 5.5 \\
\hline 6 & CFT & Chalfant Valley & 3 & 5 \\
\hline 7 & STEEL & Coalinga & 1 & 1.7 \\
\hline 8 & CFT & Coalinga & 1 & 1.2 \\
\hline 9 & STEEL & Coalinga & 2 & 4 \\
\hline 10 & CFT & Coalinga & 2 & 1 \\
\hline 11 & STEEL & Coalinga & 3 & 1.5 \\
\hline 12 & CFT & Coalinga & 3 & 0.8 \\
\hline 13 & STEEL & Northridge & 1 & 2.2 \\
\hline 14 & CFT & Northridge & 1 & 1.8 \\
\hline 15 & STEEL & Northridge & 2 & 3.6 \\
\hline 16 & CFT & Northridge & 2 & 4.2 \\
\hline 17 & STEEL & Northridge & 3 & 6 \\
\hline 18 & CFT & Northridge & 3 & 3.8 \\
\hline 19 & STEEL & Whittier Narrows & 1 & 2 \\
\hline 20 & CFT & Whittier Narrows & 1 & 1.8 \\
\hline 21 & STEEL & Whittier Narrows & 2 & 4.1 \\
\hline 22 & CFT & Whittier Narrows & 2 & 0.9 \\
\hline 23 & STEEL & Whittier Narrows & 3 & 4.5 \\
\hline 24 & CFT & Whittier Narrows & 3 & 4.7 \\
\hline
\end{tabular}

\section{Conclusion}

In the present study, the investigation and comparison of the seismic behavior of steel structures of moment frame with and without CFT column were addressed. To compare the bearing capacity and the seismic behavior of structures, the 1,2, and 3-stories models under earthquake were investigated. By investigating and comparing the displacement time history of models with and without concrete-filled columns, the following results are obtained:

- The concrete-filled steel frame has better behavior than the steel frame in terms of energy dissipation.

- Displacement of different concrete-filled frames is less than the roof displacement of steel frames which indicates the better performance of these frames.

- Presence of concrete in the steel frame has led an increase in the bearing capacity of the column under the earthquake and periodic load.

- Presence of concrete can affect the frame behavior so that the failure in the concrete-filled column occurs in the panel zone and the column has usually appropriate behavior, while in the steel frame under earthquake the buckling occurs.

- Contact and interaction of concrete and steel have led an increase in the bearing capacity of concretefilled steel column.

- In the concrete frame, the presence of concrete-filled column has led an increased load-bearing of the frame.

- Filling the steel column with concrete has prevented the inward buckling of concrete and has delayed the local buckling of the steel wall. 


\section{Reference:}

[1] Amir, F., Frank, S.Q., and Sami, R., Concrete-Filled Steel Tubes Subjected to Axial Compression and Lateral Cyclic Loads. Journal of Structural Engineering (C) ASCE / April 2004.

[2] Xiao-Ling Zhao, Raphael Grzebieta . " Strength and ductility of concrete filled double skin (SHS inner and SHS outer) tube ". ThinWalled Structures 40 (2002) 199-213.

[3] Zhong Tao, Lin-Hai Han, Xiao-Ling Zhao . " Behaviour of concrete-filled double skin (CHS inner and CHS outer) steel tubular stub columns and beam-columns". Journal of Constructional Steel Research 60 (2004) 1129-1158.

[4] Lin-Hai Han, Zhong Tao, Hong Huang, Xiao-Ling Zhao . " Concrete-filled double skin (SHS outer and CHS inner) steel tubular beamcolumns" . Thin-Walled Structures 42 (2004) 1329-1355.

[5] Zhong Tao , Lin-Hai Han . " Behaviour of concrete-filled double skin rectangular steel tubular beam-columns ". Journal of Constructional Steel Research 62 (2006) 631-646.

[6] Kojiro Uenaka, Hiroaki Kitoh, Keiichiro Sonoda . " Concrete filled double skin circular stub columns under compression " . ThinWalled Structures 48 (2010) 19-24

[7] Hong Huang, Lin-Hai Han, Zhong Tao, Xiao-Ling Zhao . " Analytical behaviour of concrete-filled double skin steel tubular (CFDST) stub columns ". Journal of Constructional Steel Research 66 (2010) 542 _555.

[8] Wei-bin Yuan, Jun-jie Yang . " Experimental and numerical studies of short concrete filled double skin composite tube columns under axially compressive loads ". Journal of Constructional Steel Research 80 (2013) 23-31

[9] M.F. Hassanein , O.F. Kharoob . " Compressive strength of circular concrete-filled double skin tubular short columns ".Thin-Walled Structures (2013), http://dx.doi.org/10.1016/j.tws.2013.10.004i .

[10] By Martin D. O'Shea,1 Member, ASCE, and Russell Q. Bridge,2 Fellow, ASCE. "DESIGN OF CIRCULAR THIN-WALLED CONCRETE FILLED STEEL TUBES” JOURNAL OF STRUCTURAL ENGINEERING / NOVEMBER 2000.126:1295-1303.

[11] Talebi, Elnaz, Manfred Korzen, and Sascha Hothan. "The performance of concrete filled steel tube columns under post-earthquake fires." Journal of Constructional Steel Research 150 (2018): 115-128.

[12] Hanifehzadeh, Mohammad, and Mir Mohammad Reza Mousavi. "PREDICTING THE STRUCTURAL PERFORMANCE OF SANDWICH CONCRETE PANELS SUBJECTED TO BLAST LOAD CONSIDERING DYNAMIC INCREASE FACTOR." Journal of Civil Engineering, Science and Technology 10, no. 1 (2019): 45-58.

[13] Wei, Yang, Cheng Jiang, and Yu-Fei Wu. "Confinement effectiveness of circular concrete-filled steel tubular columns under axial compression." Journal of Constructional Steel Research 158 (2019): 15-27.

[14] Li, Xian, Tao Zhou, Jian Li, Xiao-Bo Kuang, and Yu-Wei Zhao. "Seismic behavior of encased CFT column base connections." Engineering Structures 182 (2019): 363-378.

[15] Shariati, Mahdi, Morteza Naghipour, Ghazaleh Yousofizinsaz, Ali Toghroli, and Nima Pahlavannejad Tabarestani. "Numerical study on the axial compressive behavior of built-up CFT columns considering different welding lines." Steel and Composite Structures 34, no. 3 (2020): 377 . 